Pacific Journal of Mathematics

POLYHEDRON INEQUALITY AND STRICT CONVEXITY 


\title{
POLYHEDRON INEQUALITY AND STRICT CONVEXITY
}

\author{
B. B. Phadke
}

\begin{abstract}
This paper considers convexity of functions defined on the "Grassmann cone" of simple $r$-vectors. It is proved that the strict polyhedron inequality does not imply strict convexity.
\end{abstract}

H. Busemann, in conjunction with others, (see [3]), has considered the problem of giving a suitable definition of the convexity of functions defined on nonconvex sets. An examination of various methods of defining convexity on the "Grassmann cone" (see [1]) is found in [2]. The most important open problems (see [3]) are whether weak convexity implies the area minimizing property (also called the polyhedron inequality) and whether the latter implies convexity. A modest result in this direction is proved below, namely, the strict area minimizing property does not imply strict convexity.

2. Basic definitions. Let a continuous function $\mathscr{F}$ be defined on the Grassmann cone $G_{r}^{n}$ of the simple $r$-vectors $R$ in the linear space $V_{r}^{n}$ of all $r$-vectors $\widetilde{R}$ (over the reals). Let $\mathscr{F}$ be positive homogeneous, i.e., $\mathscr{F}(\lambda R)=\lambda \mathscr{F}(R)$ for $\lambda \geqq 0$. To a Borel set $F$ in an oriented $r$-flat $\mathscr{R}^{+}$in the $n$-dimensional affine space $A^{n}$, we associate a simple $r$-vector as follows: $R=0$ if $F$ has $r$-dimensional measure 0 , and otherwise $R=v_{1} \wedge v_{2} \wedge \cdots \wedge v_{r}$, is parallel to $\mathscr{R}^{+}$ and the measure of the parallelepiped spanned by $v_{1}, v_{2}, \cdots, v_{r}$ equals the measure of $F$. (Note a set of measure 0 and equality of measures in parallel $r$-flats are affine concepts and hence welldefined.) We denote below by $\mathscr{R}$ an $r$-flat parallel to an $r$-vector $R$ passing through the origin.

DeFINITION 1. We say that $\mathscr{F}$ has the strict area minimizing property $(S F M A)$ if: Whenever $R_{0}, R_{1}, \cdots, R_{p}$ are associated to $r$ dimensional faces of an $r$-dimensional oriented closed polyhedron $P$ we have $\mathscr{F}\left(-R_{0}\right)<\Sigma \mathscr{F}\left(R_{i}\right)$, with $i=1$ to $p$, unless $R_{i}=\lambda_{i} R_{0}, \lambda_{i} \geqq 0$ for all $i=1$ to $p$ (called the strict Polyhedron Inequality).

DeFinition 2. $\mathscr{F}$ is said to be strictly weakly convex $(S W C)$ if: Whenever $R, R_{1}$ and $R_{2}$ are simple, $R=R_{1}+R_{2}, R_{1}$ is not a scalar multiple of $R_{2}$, we have $\mathscr{F}(R)<\mathscr{F}\left(R_{1}\right)+\mathscr{F}\left(R_{2}\right)$.

Definition 3. $\mathscr{F}$ is said to be convex $(C)$ if there exists a convex extension of $\mathscr{F}$ to $V_{r}^{n}$. 
Definition 4. $\mathscr{F}$ is said to be strictly convex $(S C)$ if $\mathscr{F}$ is $C$ and if there is at least one convex extension $F$ of $\mathscr{F}$ to $V_{r}^{n}$ which satisfies the following property: Whenever $\widetilde{R}=\Sigma \widetilde{R}_{i}$ with $\widetilde{R}, \widetilde{R}_{i} \in V_{r}^{n}$, $\widetilde{R}$ is not a scalar multiple of all $\widetilde{R}_{i}$, then $F(\widetilde{R})<\Sigma F\left(\widetilde{R}_{i}\right)$.

In terms of these definitions we wish to prove below that: if $\mathscr{F}$ is $S W C$ and $C$ then it has the $S F M A$ and that if $\mathscr{F}$ is $S W C$ and $C$ it still need not be $S C$. This implies that the property $S F M A$ is weaker than the property $S C$.

3. Some algebraic facts. We collect below some algebraic facts whicn are either known or are relatively easy to prove.

(a) Let $R_{1}$ and $R_{2}$ be simple vectors. Then $R_{1}+R_{2}$ is simple if and only if $\mathscr{R}_{1}$ and $\mathscr{R}_{2}$ intersect in a flat of dimension $\geqq r-1$.

(b) Identify $r$-vectors with points representing them in $V_{r}^{n}$ considered as an affine space. If a line in $V_{r}^{n}$ contains three points corresponding to simple vectors, then the entire line consists of simple vectors. Put differently, if $R_{1}$ and $R_{2}$ are simple and $R_{i}+R_{2}$ is not simple, then the line joining $R_{1}$ and $R_{2}$ in $V_{r}^{n}$ does not contain any simple vector other than $R_{1}$ and $R_{2}$.

Suppose next that $R_{1}, R_{2}$ and $R_{3}$ are simple but that $R_{1}+R_{j}$ is nonsimple for all $i, j=1$ to 3 when $i \neq j$. Then we have the following:

(c) The set $\left\{R_{1}, R_{2}, R_{3}\right\}$ is a linearly independent set of vectors.

(d) The plane $\pi$ containing $\Delta R_{1} R_{2} R_{3}$ does not contain any line of simple vectors.

(e) The flat $\Omega$ spanned by the origin, $R_{1}, R_{2}$ and $R_{3}$ does not contain a 2-plane of simple vectors.

(f) If a line $l$ lies in $\Omega$ and does not pass through the origin, then $l$ cannot be a line of simple vectors, i.e., $l$ cannot contain three distinct points corresponding to simple vectors.

4. An example. Busemann and Straus [2] give the following concrete example which we use here to illustrate the above algebraic facts. Let the vectors $e_{1}, e_{2}, e_{3}, e_{4}$ form a base for the four dimensional affine space $A^{4}$. Denote by $e_{i j}$ the 2-vectors $e_{i} \wedge e_{j}$. Let $\Omega$ denote the flat spanned by the origin, $e_{12}, e_{34}$ and $\left(e_{1}+e_{3}\right) \wedge\left(e_{2}+e_{4}\right)$ in $V_{2}^{4}$. We denote the vectors spanning $\Omega$ by $z, R_{1}, R_{2}$ and $R_{3}$ respectively. Then $R_{i}+R_{j}$ is nonsimple for all $i, j=1$ to 3 when $i \neq j$. Thus any line $l$ in $\Omega$ which does not pass through the origin cannot contain three distinct points representing simple vectors.

5. $S W C$ with $C$ is stronger than the $S F M A$. 
Lemma A. If a function $\mathscr{F}$ is $S W C$ and $C$ then it has the SFMA.

Proof. Let $R_{0}, R_{1}, R_{2}, \cdots, R_{p}$ be $r$-vectors corresponding to $r$ faces of an $r$-dimensional oriented closed polyhedron $P$. We need consider only the case when not all $R_{i}$ are scalar multiples of $R_{0}$, $i>0$. In such a case, since $P$ is closed, some other faces which are not parallel to the face represented by $R_{0}$ intersect the face represented by $R_{0}$ in an $(r-1)$-dimensional set. Let $R_{1}$ be associated with one such face. Then from $\S 3 \mathrm{a}$ the vector $R_{0}+R_{1}$ is simple. Also since $P$ is closed we have $-\left(R_{0}+R_{1}\right)=\sum_{i=2}^{p} R_{i}$. Thus $\sum_{i=2}^{p} R_{i}$ is also simple. But then the equation: $-R_{0}=R_{1}+\sum_{i=2}^{p} R_{i}$ shows that

$$
\mathscr{F}\left(-R_{0}\right)<\mathscr{F}\left(R_{1}\right)+\mathscr{F}\left(\sum_{i=2}^{p} R_{i}\right)
$$

and, since $\mathscr{F}$ is convex, $\mathscr{F}\left(-R_{0}\right)<\sum_{i=1}^{p} \mathscr{F}\left(R_{i}\right)$ so that $\mathscr{F}$ has the SFMA.

6. Existence of functions which are $S W C$ and $C$ but not $S C$.

Lemma B. There exist functions which are $S W C$ and $C$ but not $S C$.

Proof. We actually construct an absolutely homogeneous function of this type. Take three simple unit vectors $R_{1}, R_{2}, R_{3}$ in $V_{r}^{n}$ such that $R_{i}+R_{j}$ is nonsimple for all $i, j=1$ to 3 with $i \neq j$. Choose unit vectors $\widetilde{S}_{1}, \widetilde{S}_{2}, \cdots, \widetilde{S}_{p}$ in $V_{r}^{n}$ such that the set of vectors $\left\{R_{i} \widetilde{S}_{j}\right\}$, $i=1$ to $3, j=1$ to $p$ where

$$
p=\left(\begin{array}{l}
n \\
r
\end{array}\right)-3
$$

is a base for $V_{r}^{n}$. Thus given $\widetilde{R} \in V_{r}^{n}$ we find unique numbers $\left\{a_{i}, b_{j}\right\}$ such that $\widetilde{R}=\Sigma a_{i} R_{i}+\Sigma b_{j} \widetilde{S}_{j}$. We denote this last written equality by the notation $\widetilde{R}=\left(a_{i}, b_{j}\right)$. Now define the function $\mathscr{F}$ in $V_{r}^{n}$ in the following manner:

If $\widetilde{R}=\left(a_{i}, b_{j}\right)$ then $\mathscr{F}(\widetilde{R})=\sum_{i, j}\left(a_{i}^{2}+b_{j}^{2}\right)^{1 / 2}+\left(\sum_{j} b_{j}^{2}\right)^{1 / 2}$ with $i=1$ to 3 and $j=1$ to $p$.

We verify that $\mathscr{F}$ has the required property.

(i) $\mathscr{F}$ is clearly absolutely homogeneous $(\mathscr{F}(\lambda R)=|\lambda| \mathscr{F}(R))$ and a convex function on $V_{r}^{n}$, hence convex on $G_{r}^{n}$.

(ii) We next show $\mathscr{F}$ is $S W C$. Let $R=\left(a_{i}, b_{j}\right)$ and

$$
R^{\prime}=\left(a_{i}^{\prime}, b_{j}^{\prime}\right)
$$

be two simple $r$-vectors such that $R+R^{\prime}$ is also simple. Assume 
further that $\mathscr{F}\left(R+R^{\prime}\right)=\mathscr{F}(R)+\mathscr{F}\left(R^{\prime}\right)$. We prove $\mathscr{R}$ is parallel to $\mathscr{R}^{\prime}$. Assume that $\mathscr{R}$ is not parallel to $\mathscr{R}^{\prime}$. Then the line $l$ in $V_{r}^{n}$ joining $R$ to $R^{\prime}$ is a line of simple vectors and $l$ does not pass through the origin. Therefore from the algebraic facts, $l$ does not lie in the flat $\Omega$ spanned by the origin, $R_{1}, R_{2}$ and $R_{3}$. Therefore either a $b_{j}$ or a $b_{j}^{\prime}$ is different from zero. Without loss of generality assume that $b_{1} \neq 0$. We make the simple observation that when numbers $\alpha_{i}$ and $\beta_{i}$ are such that $\alpha_{i} \leqq \beta_{i}$ and $\Sigma \alpha_{i}=\Sigma \beta_{i}$ then each $\alpha_{k}=$ $\beta_{k}$. From this and $\mathscr{F}\left(R+R^{\prime}\right)=\mathscr{F}(R)+\mathscr{F}\left(R^{\prime}\right)$ we have the following equalities:

$$
\left(\Sigma b_{j}^{2}\right)^{1 / 2}+\left(\Sigma b_{j}^{\prime 2}\right)^{1 / 2}=\left(\Sigma\left(b_{j}+b_{j}^{\prime}\right)^{2}\right)^{1 / 2}
$$

For all $(i, j)$,

$$
\left(a_{i}^{2}+b_{j}^{2}\right)^{1 / 2}+\left(a_{i}^{\prime 2}+b_{j}^{\prime 2}\right)^{1 / 2}=\left(\left(a_{i}+a_{i}^{\prime}\right)^{2}+\left(b_{j}+b_{j}^{\prime}\right)^{2}\right)^{1 / 2} .
$$

From the equality (E) we see that there exists a number $\mu$ such that

$$
\left(b_{1}^{\prime}, b_{2}^{\prime}, \cdots, b_{p}^{\prime}\right)=\mu\left(b_{1}, b_{2}, \cdots, b_{p}\right) .
$$

Also from the equalities $\left(\mathrm{E}_{i 1}\right)$ we have numbers $\mu_{i}$ such that

$$
\left(a_{i}^{\prime}, b_{1}^{\prime}\right)=\mu_{i}\left(a_{i}, b_{1}\right) \text {. }
$$

But combining $\left(\mathrm{F}_{i}\right)$ with $(\mathrm{F})$ and remembering that $b_{1} \neq 0$ we have $\mu=b_{1}^{\prime} / b_{1}=\mu_{i}$. This shows $\left(a_{i}^{\prime}, b_{j}^{\prime}\right)=\mu\left(a_{i}, b_{j}\right)$ which would mean that $\mathscr{R}$ and $\mathscr{R}^{\prime}$ are parallel. This proves $\mathscr{F}$ is $S W C$.

(iii) However, $\mathscr{F}$ is not $S C$. This can be proved as follows: Take any simple vector $R$ which is linearly dependent on $R_{1}, R_{2}, R_{3}$ say $R=a_{1} R_{1}+a_{2} R_{2}+a_{3} R_{3}$ with $a_{i} \neq 0, i=1$ to 3 . Then we have $\mathscr{F}(R)=\left|a_{1}\right|+\left|a_{2}\right|+\left|a_{3}\right|=\mathscr{F}\left(a_{1} R_{1}\right)+\mathscr{F}\left(a_{2} R_{2}\right)+\mathscr{F}\left(a_{3} R_{3}\right)$, which violates strict inequality even on $G_{r}^{n}$. Consequently it is impossible to extend $\mathscr{F}$ to a strictly convex function on $V_{r}^{n}$. We note here that in the example of $\S 4$ all vectors $a_{1} R_{1}+a_{2} R_{2}+\left(-a_{1} a_{2} / a_{1}+a_{2}\right) R_{3}$ are simple. This completes the proof of Lemma $B$.

7. THEOREM. The strict area minimizing property does not imply strict convexity.

Proof. By Lemma A we have the SFMA implied by $S W C$ and $C$. But by Lemma B, $S W C$ and $C$ do not imply $S C$. Hence, the $S F M A$ does not imply $S C$. Briefly $S F M A \leqq S W C+C<S C$.

Suggestions for this paper from Professor H. Busemann are gratefully acknowledged. 


\section{REFERENCES}

1. N. Bourbaki, Algèbre Multilinéaire, Elements de Math, I, livre II, Chap. 3, Paris, 1958.

2. H. Busemann, and E. G. Straus, Area and normality, Pacific J. Math. 10 (1960), $35-72$.

3. H. Busemann, and G. C. Shephard, Convexity on nonconvex sets, Proc. Coll. Convexity, Copenhagen, 1965, (1967), 20-33.

Received October 16, 1968. This work was partially supported by the National Science Foundation under Grant No. GP-7472.

University of SOUthern California, Los ANgeles 



\section{PACIFIC JOURNAL OF MATHEMATICS}

\section{EDITORS}

H. ROYDEN

Stanford University

Stanford, California

\section{RichaRd PIERCE}

University of Washington Seattle, Washington 98105
J. DugundJI

Department of Mathematics

University of Southern California

Los Angeles, California 90007

BASIL GORDON

University of California

Los Angeles, California 90024

\section{ASSOCIATE EDITORS}
E. F. BECKENBACH
B. H. NeUMANN
F. WOLF
K. YOSHIDA

\section{SUPPORTING INSTITUTIONS}

UNIVERSITY OF BRITISH COLUMBIA CALIFORNIA INSTITUTE OF TECHNOLOGY

UNIVERSITY OF CALIFORNIA

MONTANA STATE UNIVERSITY

UNIVERSITY OF NEVADA

NEW MEXICO STATE UNIVERSITY

OREGON STATE UNIVERSITY

UNIVERSITY OF OREGON

OSAKA UNIVERSITY

UNIVERSITY OF SOUTHERN CALIFORNIA

\author{
STANFORD UNIVERSITY \\ UNIVERSITY OF TOKYO \\ UNIVERSITY OF UTAH \\ WASHINGTON STATE UNIVERSITY \\ UNIVERSITY OF WASHINGTON \\ AMERICAN MATHEMATICAL SOCIETY \\ CHEVRON RESEARCH CORPORATION \\ TRW SYSTEMS \\ NAVAL WEAPONS CENTER
}

The Supporting Institutions listed above contribute to the cost of publication of this Journal, but they are not owners or publishers and have no responsibility for its content or policies.

Mathematical papers intended for publication in the Pacific Journal of Mathematics should be in typed form or offset-reproduced, double spaced with large margins. Underline Greek letters in red, German in green, and script in blue. The first paragraph or two must be capable of being used separately as a synopsis of the entire paper. It should not contain references to the bibliography. Manuscripts, in duplicate if possible, may be sent to any one of the four editors. Please classify according to the scheme of Math. Rev. 36, 1539-1546. All other communications to the editors should be addressed to the managing editor, Richard Arens, University of California, Los Angeles, California, 90024.

50 reprints are provided free for each article; additional copies may be obtained at cost in multiples of 50 .

The Pacific Journal of Mathematics is published monthly. Effective with Volume 16 the price per volume (3 numbers) is $\$ 8.00$; single issues, $\$ 3.00$. Special price for current issues to individual faculty members of supporting institutions and to individual members of the American Mathematical Society: $\$ 4.00$ per volume; single issues $\$ 1.50$. Back numbers are available.

Subscriptions, orders for back numbers, and changes of address should be sent to Pacific Journal of Mathematics, 103 Highland Boulevard, Berkeley, California, 94708.

PUBLISHED BY PACIFIC JOURNAL OF MATHEMATICS, A NON-PROFIT CORPORATION

Printed at Kokusai Bunken Insatsusha (International Academic Printing Co., Ltd.), 7-17. Fujimi 2-chome, Chiyoda-ku, Tokyo, Japan. 


\section{Pacific Journal of Mathematics}

\section{Vol. 30, No. $3 \quad$ November, 1969}

Willard Ellis Baxter, Topological rings with property $(Y) \ldots \ldots \ldots \ldots . \ldots 5$

Sterling K. Berberian, Note on some spectral inequalities of $C . R$.

Putnam ..................................... 573

David Theodore Brown, Galois theory for Banach algebras . ........... 577

Dennis K. Burke and R. A. Stoltenberg, A note on p-spaces and Moore spaces ........................................ 601

Rafael Van Severen Chacon and Stephen Allan McGrath, Estimates of positive contractions....................................... 609

Rene Felix Dennemeyer, Conjugate surfaces for multiple integral problems in the calculus of variations ........................... 621

Edwin O. Elliott, Measures on countable product spaces.............. 639

John Moss Grover, Covering groups of groups of Lie type .............. 645

Charles Lemuel Hagopian, Concerning semi-local-connectedness and cutting in nonlocally connected continua .................. 657

Velmer B. Headley, A monotonicity principle for eigenvalues ........... 663

John Joseph Hutchinson, Intrinsic extensions of rings . . . . . . . . . . . . . 669

Harold H. Johnson, Determination of hyperbolicity by partial

prolongations .................................. 679

Tilla Weinstein, Holomorphic quadratic differentials on surfaces in $E^{3} \ldots 697$

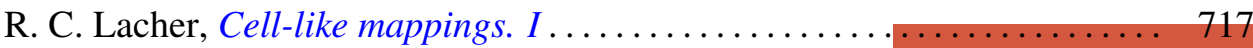

Roger McCann, A classification of centers

Curtis L. Outlaw, Mean value iteration of nonexpansive mappings in a

Banach space...

Allan C. Peterson, Distribution of zeros of solutions of a fourth order

differential equation.

Bhalchandra B. Phadke, Polyhedron inequality and strict convexity .. 765 Jack Wyndall Rogers Jr., On universal tree-like continua .

Edgar Andrews Rutter, Two characterizations of quasi-Frobenius rings

G. Sankaranarayanan and C. Suyambulingom, Some renewal theorems concerning a sequence of correlated random variables...

Joel E. Schneider, A note on the theory of primes........ . .

Richard Peter Stanley, Zero square rings .................

Edward D. Tymchatyn, The 2-cell as a partially ordered space

Craig A. Wood, On general Z.P.I.-rings................ 